Таджибова Лариса Низамиевна

кандидат социологических наук, доцент кафедры философии и социальных коммуникаций Санкт-Петербургского государственного университета гражданской авиации

\section{РЕАЛИЗАЦИЯ КОРПОРАТИВНЫХ СОЦИАЛЬНЫХ ПРОГРАММ КАК ПРАКТИКА СОЦИАЛЬНОГО ПАРTHEРCTBA}

\begin{abstract}
Аннотация:
Существующие противоречия интересов наемных работников, собственников и менеджеров организаций определяют необходимость формирования эффективной системы регулирования социально-трудовых отношений и, следовательно, актуальность научного анализа института социального партнерства. В статье рассматривается институциональный подход к изучению подобного партнерства на уровне организации. В его рамках социальное партнерство трактуется как общественный институт, регулирующий взаимодействие работодателей и наемных сотрудников, обеспечивающий согласование их интересов по актуальным вопросам совместной деятельности. Отмечается, что развитие этого института на уровне организации проявляется в формировании устойчивых практик взаимодействия субъектов социально-трудовых отношений. Такими практиками в ряде российских компаний являются заключение коллективных договоров, совместная разработка и реализация социальных программ. Автор анализирует опыт принятия корпоративных социальных программ, исследует их основные направления и содержание, влияние их реализации на эффективность деятельности предприятия.
\end{abstract}

Ключевые слова:

социально-трудовые отношения, институциональный подход, институт социального партнерства, субъекты социального партнерства, практики социального партнерства, коллективные переговоры, коллективный договор, корпоративные социальные программы.
Tadzhibova Larisa Nizamievna

PhD in Sociology, Associate Professor, Department of Philosophy and Social Communications, St. Petersburg State University of Civil Aviation

\section{IMPLEMENTATION OF CORPORATE} SOCIAL PROGRAMS AS A PRACTICE OF SOCIAL PARTNERSHIP

\begin{abstract}
Summary:
The existing contradictions in the interests of employees, owners, and managers of organizations indicate the need for an effective system for regulating social and labor relations and determine the relevance of scientific research of the institute of social partnership. The paper focuses on the institutional approach to the study of social partnership at the organizational level. In the framework of this approach, social partnership is viewed as a public institute that regulates interaction of employers and employees, ensuring coordination of their interests on topical issues of joint activities. It is noted that the development of the institute of social partnership at the organizational level is manifested in the formation of sustainable practices of interaction between owners, managers, and employees. In a number of Russian companies such practices are represented by collective employment contracts and joint development and implementation of social programs. The author analyzes the experience of implementing corporate social programs, studies their main areas and contents, their impact on the company efficiency.
\end{abstract}

Keywords:

social and labor relations, institutional approach, institute of social partnership, subjects of social partnership, practices of social partnership, collective negotiation, collective employment contract, corporate social programs.

Проблема совершенствования сферы социально-трудовых отношений является одной из наиболее значимых в современном российском социуме. Данные отношения - важнейшая область реализации принципа социальной справедливости и один из факторов поступательного общественного развития. Именно в сфере труда выявляются и согласовываются противоречивые интересы общественных групп, удовлетворяются их потребности.

Данные социологических исследований показывают, что социально-трудовые отношения в современной России характеризуются обострением противоречий интересов наемных работников и собственников, руководителей организаций и предприятий. В частности, в 2019 г. зарегистрировано 134 трудовых конфликта на территории РФ. Отмечается тенденция возрастания количества протестных публичных акций работников в ходе трудовых конфликтов. За период с 2017 по 2019 г. увеличилась средняя продолжительность трудовых конфликтов с 15 до 28 дней, а также доля «длинных» споров, продолжающихся от полугода и более [1].

Основными причинами повышения напряженности в сфере труда на уровне организации являются такие экономические и финансовые проблемы хозяйствующих субъектов, как ликвидация предприятия, угроза банкротства, остановка работодателем производства на неопределен- 
ный срок, увольнение сотрудников, снижение заработной платы, ухудшение условий труда в отдельных отраслях и регионах. Существующие противоречия интересов наемных работников, собственников и менеджеров определяют необходимость формирования эффективной системы регулирования социально-трудовых отношений. В условиях преобладания частной собственности на средства производства подобным механизмом выступает социальное партнерство как система взаимодействий работодателей и наемных работников, направленная на согласование их интересов по актуальным вопросам социально-трудовых отношений.

Представляется обоснованным исследование социального партнерства с теоретических позиций институционального подхода. В социологической науке различные аспекты данного подхода к изучению общественных процессов получили развитие в работах О. Конта, Г. Спенсера, К. Маркса, Э. Дюркгейма, Т. Веблена, М. Вебера, Т. Парсонса, Р. Мертона, Д. Норта. Указанный подход к анализу трансформационных процессов современного российского общества отражен в трудах отечественных социологов Д.П. Гавры, Т.И. Заславской, В.В. Радаева, П.В. Разова [2].

В рамках институционального подхода общество рассматривается как система, мегаструктура, развивающаяся на основе функционирования социальных институтов (от лат. institutum 'установленный'). Последний можно трактовать как сложившийся устойчивый комплекс норм и правил, образцов поведения, регулирующих взаимодействия в определенной сфере общественных отношений. Социальные институты выполняют значимые функции, обеспечивающие стабильность и развитие социума. Институциональный подход предполагает изучение развития общества посредством анализа формирования социальных норм и правил, а также складывающихся устойчивых образцов (практик) поведения социальных субъектов в разных областях общественных отношений.

Таким образом, в рамках данного теоретического подхода социальное партнерство в сорере труда можно рассматривать как общественный институт, регулирующий взаимодействие работодателей и наемных работников, обеспечивающий согласование их интересов по актуальным вопросам совместной деятельности. Теоретический анализ институциональной структуры социального партнерства предполагает выделение следующих элементов: формальных норм, принимаемых государством, социальных ролей субъектов социально-трудовых отношений, практик взаимодействия этих субъектов.

Формирование института социального партнерства в сфере труда в развитых капиталистических странах происходило постепенно и явилось результатом действия таких фракторов, как длительная борьба рабочих за свои права, развитие профсоюзного движения, осуществление в условиях экономического кризиса целенаправленной государственной социальной политики, выразившейся в совершенствовании трудового законодательства.

С началом реформ 1990-х гг., приведших к трансформации структуры собственности, в России стала складываться новая система социально-трудовых отношений, заменившая советскую модель. На государственном уровне принципы социального партнерства были определены как основа новой модели этих отношений, что выразилось в создании соответствующей нормативной базы. Начался процесс формирования трех- и двустороннего взаимодействия государства, работодателей и профсоюзов на федеральном, региональном, отраслевом и организационном уровнях, предусматривающий заключение соглашений по ключевым вопросам трудовой и производственной деятельности. В настоящее время в России действуют Генеральное соглашение на 2018-2020 гг., 64 федеральных отраслевых соглашения, 79 региональных трехсторонних соглашений, 1814 территориальных трехсторонних соглашений, 4599 отраслевых соглашений регионального и территориального уровней, 130727 коллективных договоров [3, с. 25].

С начала 1990-х гг. различные аспекты развития социального партнерства в России получили освещение в работах отечественных социологов. В их числе нужно отметить исследования В.Ю. Бочарова, Н.М. Карамышевой, С.И. Кубицкого, Б.И. Максимова, А.Л. Темницкого, В.Н. Шаленко [4]. 3начимым является анализ российской модели социального партнерства, представленный в трудах научного коллектива Санкт-Петербургского гуманитарного университета профсоюзов под руководством Д.В. Лобок [5]. В настоящее время одним из актуальных направлений изучения социального партнерства выступает анализ различных аспектов его развития на уровне организации.

Развитие института социального партнерства в сфере труда выражается в возникновении устойчивых фрорм взаимодействия работодателей и наемных работников - социальных практик. Важнейшим уровнем социального партнерства является организация как место осуществления производственной деятельности, объединяющей собственников, менеджеров и сотрудников. Именно поэтому актуальным направлением исследования указанного института служит анализ практик, реализуемых участниками социально-трудовых отношений в компании.

К настоящему времени наиболее сформировавшейся практикой социального партнерства на уровне организации являются коллективные переговоры в целях заключения коллективного 
договора. Вместе с тем исследование деятельности российских компаний позволяет заключить, что, помимо принятия таких соглашений, в ряде успешно развивающихся корпораций осуществляется и такая практика социального партнерства, как реализация социальных программ на базе совместных консультаций руководства и кадрового состава. В числе таких предприятий следует назвать ПАО «Газпром», ПАО «Норильский никель», ПАО «Магнитогорский металлургический комбинат», ПАО «Лукойл». Применение методов кейс-стади, анализа документов - корпоративных социальных отчетов, отчетов об устойчивом развитии - позволяет сделать вывод, что руководство здесь ведет целенаправленную политику в сфере социально-трудовых отношений, в рамках которой персонал рассматривается как главная ценность компании, а его представители привлекаются к реализации корпоративной социальной политики. Коллективный договор и социальные программы служат основным инструментом совершенствования указанных отношений.

Например, в компании ПАО «Газпром» развиваются следующие формы взаимодействия руководства и кадрового состава:

- семинары-совещания работников служб по управлению персоналом;

- горячая линия по вопросам противодействия мошенничеству, коррупции и хищениям;

- регулярные встречи представителей трудовых коллективов и руководства, посвященные решению актуальных вопросов совместной деятельности;

- сотрудничество с международными нефтегазовыми компаниями по вопросам обучения [6].

Интересы работников ПАО «Газпром» представляет межрегиональная профсоюзная организация «Газпром профсоюз». Генеральный коллективный договор является основным документом, регламентирующим социальную политику корпорации, в которой реализуются следующие направления социального партнерства: совершенствование и развитие механизма коллективных переговоров участников трудовых отношений, создание системы эффективной мотивации персонала компании.

В ПАО «Газпром» действует такая форма социального партнерства, как совместная разработка и реализация корпоративных социальных программ. В организации работает комплексная программа повышения эффективности управления человеческими ресурсами на период 2016-2020 гг. [7]. В соответствии с ней приняты следующие направления совершенствования кадровой политики:

- планирование трудовых ресурсов;

- подбор персонала и комплектование штата компании;

- обучение и развитие персонала;

- мотивация сотрудников;

- корпоративные коммуникации;

- информационное обеспечение.

В корпорации осуществляется программа постоянного профессионального образования сотрудников, учитывающая новые требования производства и качества труда, совершенствование технологий, расширение сферы деятельности. Также в компании действуют социальная программа обеспечения жильем, предусматривающая применение банковского ипотечного кредитования; программа пенсионного обеспечения сотрудников.

Представляют интерес практики социального партнерства, реализуемые в компании ПАО «Норильский никель». Одним из провозглашаемых принципов корпоративного управления здесь является соблюдение баланса интересов акционеров, менеджмента, работников компании и иных заинтересованных сторон. Важным направлением управленческой стратегии выступает формирование комплекса мероприятий по повышению уровня вовлеченности персонала в процесс принятия решений, стимулированию работников совершенствовать профессиональные навыки.

В компании интересы кадрового состава представляют социально-трудовые советы и профрсоюзные организации. По данным за 2018 г. 78,0 \% общей численности сотрудников являлись членами социально-трудовых советов, 10,8 \% - состояли в профсоюзах [8]. Кроме того, на предприятиях корпорации действуют и другие рабочие органы коллегиального принятия решений, включающие представителей работодателя, работников и профсоюзов. К ним относятся следующие структуры:

- совместные комиссии, комитеты, рабочие группы;

- советы трудовых коллективов;

- приемные по производственным и социально-трудовым вопросам;

- корпоративный форум.

В качестве совместных коллегиальных органов, обеспечивающих участие персонала в управлении, на предприятиях ПАО «Норильский Никель» работают комиссии по регулирова- 
нию социально-трудовых отношений, заключению коллективных договоров. В корпорации действуют генеральный коллективный договор на период 2018-2021 гг., а также 21 коллективный договор, охватывающий 81 \% от среднесписочной численности сотрудников [9].

В ПАО «Норильский никель» реализуются следующие направления социальных программ:

- переквалификация высвобождаемого персонала в целях трудоустройства на других производствах компании;

- поддержание работников и членов их семей, а также бывших работников предприятий;

- совершенствование управленческих компетенций руководителей высшего уровня;

- развитие целевых групп персонала, к которым относятся молодые сотрудники, линейные руководители, высококвалифицированные рабочие.

В числе механизмов, направленных на обучение кадрового состава, следует упомянуть программу по развитию управленческих компетенций «Управленческий старт» для впервые назначенных руководителей производственных подразделений; сквозные программы по развитию всех категорий руководителей; программу переподготовки работников предприятий, предусматривающую возможность обучения на базе корпоративных учебных центров. Примерами эффективно реализуемых социальных инструментов являются также корпоративная программа негосударственного пенсионного обеспечения «Накопительная долевая пенсия», действующая с 2007 г.; программа «Ветераны компании», ориентированная на поддержку неработающих пенсионеров, постоянно проживающих на территории Норильска.

Большой интерес представляет анализ социальной деятельности ПАО «Магнитогорский металлургический комбинат». Конструктивное взаимодействие руководства и трудового коллектива компании осуществляется посредством системы регулярных консультаций и встреч, функционирования интернет-приемной председателя профсоюзного комитета. Система социальнотрудовых отношений в организации регулируется коллективным договором.

Кроме того, компания разрабатывает и реализует социальные программы, главными целями которых являются всестороннее развитие персонала, создание благоприятных условий труда. Основными направлениями подобных программ выступают обучение и профессиональная подготовка, повышение квалификации сотрудников, предоставление социального пакета, создание схемы мотивации труда, обеспечение благоприятных условий работы и отдыха [10].

Большую роль в социальной политике компании играют программы по социальной защите сотрудников. Главными направлениями данных программ являются реализация мер по оказанию медицинских услуг сотрудникам; предоставление социальных льгот пенсионерам, инвалидам, многодетным семьям, помощи в приобретении жилья; работа с молодыми сотрудниками; проведение культурных и спортивных мероприятий.

Компания ПАО «Лукойл» осуществляет регулирование социально-трудовых отношений на базе принципов социальной ответственности, закрепленных в социальном кодексе компании, соглашении между работодателем и профобъединением, коллективных договорах. Основой реализации социальной политики являются долгосрочные программы, направленные на формирование высококвалифицированного персонала. Главной проблематикой таких программ выступают развитие кадрового состава, охрана здоровья, добровольное медицинское страхование, негосударственное пенсионное обеспечение, страхование от несчастных случаев, помощь в приобретении жилья, поддержка материнства и семей с детьми.

В качестве основных направлений корпоративных программ развития персонала можно выделить обучение, повышение квалификации и профессиональную переподготовку сотрудников, проведение семинаров и тренингов, внедрение современных методов оценки и подготовки трудового коллектива, развитие системы дистанционного и электронного обучения, сотрудничество с высшими учебными заведениями. В ПАО «Лукойл» реализуется комплексная целевая программа по взаимодействию с молодыми работниками и специалистами, нацеленная на фрормирование кадрового потенциала компании [11].

Важную роль в управленческой практике рассмотренных организаций играет регулярный мониторинг внутреннего социально-психологического климата, удовлетворенности условиями труда сотрудников. Подобные исследования являются эффрективным инструментом профилактики возникновения конфликтных ситуаций.

Анализ социальной деятельности ведущих российских корпораций позволяет сделать следующие выводы. Развитие института социального партнерства в России на организационном уровне проявляется в практиках взаимодействия работодателей и наемных работников, реализуемых в ряде успешно развивающихся отечественных компаний. Такими практиками выступают коллективные переговоры и совместные консультации представителей администрации и персонала в целях заключения коллективных договоров и принятия социальных программ. Институци- 
ализация практик социального партнерства выражается в постоянном фрункционировании совместных структур, объединяющих представителей администрации и кадрового состава, таких как совместные комиссии и комитеты, советы трудовых коллективов.

Совместные подготовка и реализация корпоративных социальных программ являются перспективной фрормой социального партнерства руководства и персонала. Работа над принятием социальных программ создает дополнительные возможности взаимодействия менеджмента и представителей трудового коллектива, позволяет учитывать интересы сторон в осуществлении социальной политики. Внедрение таких программ способствует повышению эффективности деятельности сотрудников, повышает их вовлеченность в достижение корпоративных целей, а также подготавливает основу для участия в управлении предприятием. Развивающиеся практики реализации социальных программ выступают одним из направлений институциализации социального партнерства на уровне организации, что определяет актуальность их дальнейшего исследования.

\section{Ссылки:}

1. Социально-трудовые конфрликты в Российской Федерации. Предварительные итоги 2019 г. [Электронный ресурс] // Социально-трудовые конфликты. Мониторинг. Анализ. Прогноз. 2019. 8 нояб. URL: http://industrialconflicts.ru/lib/70 (дата обращения: 14.01.2020).

2. Гавра Д.П. Категория социального института в социологии (история понимания и современные подходы; сущность, структура и основные признаки) // Регион: политика, экономика, социология. 1999. № 1. С. 79-83 ; Заславская Т.И. Социетальная трансформация российского общества: деятельностно-структурная концепция. М., 2002. 568 с. ; Радаев В.В. Что такое рынок: экономико-социологический подход // Общественные науки и современность. 2007 . № 3. С. 117-132 ; Разов П.В. Институциональный подход и возможности его применения в социологии управления // Apмия и общество. 2012. № 3 (31). С. 19-23.

3. ФНПР сегодня. От ІХ к Х съезду ФНПР (2015-2019 гг.) : информационный сборник. М., 2019. 132 с. [Электронный ресурс] // Федерация независимых профосоюзов России. 2019. 18 июня. URL: http://www.fnpr.ru/n/316/17892.html (дата обращения: 14.01.2020)

4. Бочаров В.Ю. Институциализация договорных трудовых отношений на предприятиях // Социологические исследования. 2001. № 7. С. 63-68 ; Карамышева Н.М. Приватизация и трудовые отношения: от единого и общего - к частному и разному // Журнал социологии и социальной антропологии. 2004. Т. 7, № 2 (26). С. 182-195; Кубицкий С.И. Социальное партнерство в России: состояние и перспективы. М., 1999. 184 с. ; Максимов Б.И. Положение и социально-трудовые права рабочих в 1990-е гг. // Журнал социологии и социальной антропологии. 2004. Т. 7, № 3 (27). С. 46-72 ; Темницкий А.Л. Ориентации рабочих на патерналистские и партнерские отношения с руководством // Социологические исследования. 2004. № 6 (242). С. 26-37 ; Шаленко В.Н. Трудовые конфликты: методология, теория и управление. М., 2008. 321 с.

5. Коллективный договор как механизм предотвращения социально-трудовых конфоликтов / Д.В. Лобок, Г.М. Бирженюк, А.А. Васецкий [и др.] ; науч. ред. А.С. Запесоцкий. СПб., 2018. 182 с.

6. В интересах человека: отчет о деятельности в области устойчивого развития за 2018 г. [Электронный ресурс] // ПАО «Газпром». URL: https://sustainability.gazpromreport.ru/2018 (дата обращения: 14.01.2020).

7. Там же.

8. Новый Норникель: стратегия в действии. Отчет об устойчивом развитии 2018 г. [Электронный ресурс] // ПАО «ГМК "Норильский Никель"». URL: https://www.nornickel.ru/files/ru/CSOpdf/NN_SR2018.pdf (дата обращения: 14.01.2020).

9. Там же.

10. Социальный отчет 2018 г. [Электронный ресурс] // ПАО «Магнитогорский металлургический комбинат». URL: http://mmk.ru/upload/medialibrary/51a/soc_otch_2018.pdf (дата обращения: 14.01.2020).

11. Наш вклад в цели устойчивого развития ООН в 2018 г. Отчет о деятельности в области устойчивого развития группы «Лукойл» [Электронный ресурс] // Нефртяная компания «Лукойл». URL: https://csr2018.lukoil.ru (дата обращения: 14.01.2020).

\section{References:}

Bocharov, VYu 2001, 'Institutionalization of Contract Employment Relations in Companies', Sotsiologicheskie issledovaniya, no. 7, pp. 63-68, (in Russian).

Federation of Independent Labor Unions of Russia 2019, Federation of Independent Labor Unions of Russia Today. From $9^{\text {th }}$ to $10^{\text {th }}$ Federation's Session (2015-2019): Information Collection, Moscow, 132 p., viewed 14 January 2020, <http://www.fnpr.ru/n/316/17892.html>, (in Russian).

Gavra, DP 1999, 'The Category of Social Institute in Sociology (the History of Understanding and Modern Approaches; Essence, Structure, and Main Features)', Region: politika, ekonomika, sotsiologiya, no. 1, pp. 79-83, (in Russian).

Karamysheva, NM 2004, 'Privatization and Employment Relations: From Single and General to Special and Different', Zhurnal sotsiologii i sotsialnoi antropologii, vol. 7, no. 2 (26), pp. 182-195, (in Russian).

Kubitskiy, SI 1999, Social Partnership in Russia: Current State and Prospects, Moscow, 184 p., (in Russian).

Lobok, DV, Birzhenyuk, GM, Vasetsky, AA, Zapesotsky, AS (ed.) et al. 2018, Collective Employment Agreement as a Mechanism to Prevent Social and Labor Disputes, St. Petersburg, 182 p., (in Russian).

Maksimov, BI 2004, 'Position and Social and Labor Rights of Workers in 1990s', Zhurnal sotsiologii i sotsialnoi antropologii, vol. 7 , no. 3 (27), pp. 46-72, (in Russian).

Monitoring and Analysis Center 'Labor Disputes' 2019, Social and Labor disputes in the Russian Federation (Preliminary

Results for 2019), 9 p., viewed 14 January 2020, <http://industrialconflicts.ru/i/msg2 i/37/prezantatsiya.pdf>, (in Russian).

PJSC Gazprom 2018, In the Best Interest of People: Report on Activity in the Field of Sustainable Development for the Year 2018, 208 p., viewed 14 January 2020, <https://sustainability.gazpromreport.ru/2018>, (in Russian).

PJSC Magnitogorsk Iron 2018, Social Report 2018, 44 p., viewed 14 January 2020, <http://mmk.ru/upload/medialibrary/51a/soc_otch_2018.pdf>, (in Russian). 
PJSC MMMC Norilsk Nickel 2018, New Nornickel: Strategy in Action. Report on Sustainable Development 2018,86 p., viewed 14 January 2020, <https://www.nornickel.ru/files/ru/CSOpdf/NN_SR2018.pdf>, (in Russian).

Radaev, VV 2007, 'What is Market: Economics and Sociological Approach', Obschestvennie nauki i sovremennost, no. 3 , pp. 117-132, (in Russian).

Razov, PV 2012, 'Institutional Approach and Opportunities of its Application in Sociology of Management', Armiya i obschestvo, no. 3 (31), pp. 19-23, (in Russian).

Shalenko, VN 2008, Labor Disputes: Methodology, Theory and Management, Moscow, 321 p., (in Russian).

Temnitsky, AL 2004, 'Orientation of Workers on Paternalistic and Partner Relations with Managers', Sotsialnie issledovaniya, no. 6 (242), pp. 26-37, (in Russian).

Zaslavskaya, TI 2002, Societal Transformation of the Russian Society: Activity and Structural Conception, Moscow, 568 p., (in Russian).

Редактор: Тюлюкова Мария Олеговна Переводчик: Жбан Екатерина Сергеевна 